\title{
The importance of diet in osteoporosis
}

\author{
Nicolás Mendoza ${ }^{1 *}$ Jesús Presa $^{2}$, Antonio Martínez-Amat ${ }^{3}$, Fidel Hita ${ }^{3}$ \\ ${ }^{1}$ Department of Obstetrics and Gynecology, University of Granada, Granada, Spain \\ ${ }^{2}$ Department of Obstetrics and Gynecology, Hospital Princesa Sofia, Jaen, Spain \\ ${ }^{3}$ Department of Health Sciences, University of Jaen, Jaen, Spain \\ Email: ${ }^{*}$ nicomendoza@telefonica.net, ipresalorite@hotmail.com, amat103@ugr.es, fhita@ujaen.es
}

Received 13 December 2012; revised 18 January 2013; accepted 27 January 2013

Copyright (C) 2013 Nicolás Mendoza et al. This is an open access article distributed under the Creative Commons Attribution License, which permits unrestricted use, distribution, and reproduction in any medium, provided the original work is properly cited.

\begin{abstract}
The knowledge of risk factors associated with the development of osteoporosis (OP) is vital in the prevention strategy of this disease and its physical and economic consequences. The epidemiological characteristics of our population of postmenopausal women exhibit a pattern similar to that described in other studies, showing a proportional relationship between the magnitude of the risk factor and the severity of osteopenia/osteoporosis. Moreover, we observed protective effects for several dietary factors, such as the consumption of fruits, vegetables, and cereals; the moderate consumption of fish, alcohol, and dairy products; and the low intake of red meat, on spinal bone mineral density (BMD). Only the intake of grains and vegetables exerted protective effects on hip BMD.
\end{abstract}

Keywords: Osteoporosis; Diet; Risk Factors

\section{INTRODUCTION}

Osteoporosis fractures and bone mass loss are important health care problems affecting the majority of elderly individuals in developed countries. The knowledge of risk factors associated with the development of osteoporosis (OP) is vital in the prevention strategy of this disease and its physical and economic consequences. However, diagnostic modalities and factors which identified in the epidemiology of OP have not succeeded in identifying all patients who are in danger of presenting with a fracture due to fragility [1].

Some of the risk factors that have been described for osteoporosis, such as age, sex, and race, are intrinsic and therefore cannot be changed; others, such as diet, lifestyle, situations that increase the risk of falls, or the consumption of certain drugs, are extrinsic and can be modi-

\footnotetext{
"Corresponding author.
}

fied. Moreover, the evaluation of several risk factors may be as important as the value of bone density screening [2].

In recent years, there has been significant interest in the influence of diet on bone metabolism. Several studies have shown that alkaline diets (high in magnesium, potassium, fruit, and vegetables) improve bone mineral density (BMD) and prevent the loss of bone mass compared with acidic diets (protein) [3].

The aim of this study was to describe the epidemiological characteristics of a population of postmenopausal women with osteopenia or osteoporosis in our environment and to determine whether specific dietary factors are present. Furthermore, we intended to differentiate women with low BMD in cortical bone (spine) from those who have low BMD in trabecular bone (hip) to determine whether these dietary influences have greater effects on specific types of bone.

\section{MATERIALS AND METHODS}

The study population consisted of 1980 postmenopausal Spanish women (post-hysterectomy or after one year without menstruation) who consulted a gynaecologist for advice about bone health. All participants received written information about the objective of the study and gave written consent to participate.

The clinical data were obtained using a structured questionnaire that was developed in consensus by the clinical investigators involved in the study. This questionnaire collects specific information about known risk factors for OP as well as other factors considered in our study. This project was approved by the ethics committees of each hospital involved in the study.

Patients who were premenopausal, did not complete the questionnaire completely, who were receiving any type of treatment for OP at the time of the study, or for whom bone absorptiometry or genetic information was not available were excluded. BMD data were obtained 
from participants using double energy x-ray densitometers using a Hologic QDR 1000/W instrument in 72.6\% of cases and a Norland densitometer in the remainder of cases. To solve the problem of obtaining data through two different measurement systems, the value of the $\mathrm{T}$ score was used for statistical calculations, with $\mathrm{T}$ scores greater than $-1.0 \mathrm{SD}$ considered normal, values between $-1.0 \mathrm{SD}$ and $-2.5 \mathrm{SD}$ considered indicative of osteopenia, and values less than $-2.5 \mathrm{SD}$ considered indicative of OP. BMD data $\left(\mathrm{gr} / \mathrm{cm}^{2}\right)$ were also obtained using the total value of the lumbar spine (L2 through L4) as a reference for the measurement of spongy BMD and using the value of the femoral neck as a reference for the cortical BMD of the femur.

\section{Statistical Analysis}

A descriptive study and a bivariate analysis of the data were performed using the statistical program SPSS 15.0. For dichotomous variables, the Chi-square test was corrected through the Yates test when the percentage of cells with an expected frequency less than 5 was $20 \%$ or less. If these conditions were not met, then the correction was made using the Fisher test. Qualitative variables with more than two categories were compared with the Chi-square test, and correction by grouping categories was attempted if more than $20 \%$ of cells had an expected frequency less than five.

When the independent variables were numerical, their normality was first tested with the Kolmogorov-Smirnov contrast; then, the Student's t-test or the Mann Whitney
U-test was subsequently applied, depending on whether the variable was distributed normally or not, respectively.

\section{RESULTS}

The study included 450 postmenopausal women in the osteoporosis group, 766 women in the osteopenia group, and 479 women in the control group. The demographic characteristics of the population are given in Tables $\mathbf{1}$ and 2. Women with lower weight and height exhibited lower BMD, both in the lumbar spine and in the hip. The age of menarche and age of menopause were collected to delimit the period of estrogenic activity. Later menarche and earlier menopause were observed in the group of women with the most advanced osteoporosis. Consistent with this finding, there were significantly more cases of praecox menopause (occurring before 40 years of age) among patients with osteoporosis. There were no statistically significant correlations between any of the parameters and hip BMD due to the small sample size.

With regard to extrinsic factors (i.e., diet, exercise, and other habits) related to the development of osteoporosis in women, our study found a direct relationship between tobacco consumption and BMD and an inverse relationship between moderate alcohol consumption and lumbar spine BMD. We define as "moderate alcohol consumer" the women who drink one to four glasses of wine or beer a week. These associations were not detected in the femoral neck. Neither physical exercise nor fat distribution was associated with different BMDs (Tables 3 and 4).

Table 1. Demographic characteristics and BMD at lumbar spine.

\begin{tabular}{|c|c|c|c|c|}
\hline & $\begin{array}{l}\text { Normal } \\
\mathrm{N}=479\end{array}$ & $\begin{array}{c}\text { Osteopenia } \\
N=766\end{array}$ & $\begin{array}{c}\text { OP } \\
N=450\end{array}$ & \\
\hline $\mathrm{Age}^{*}$ & $62 \pm 8.14$ & $62 \pm 8.12$ & $62 \pm 8.10$ & NS \\
\hline Weight ${ }^{*}$ & $69.68 \pm 11.44$ & $65.89 \pm 10.41$ & $63.40 \pm 9.87$ & $\mathrm{p}<0.05$ \\
\hline Height $^{*}$ & $158.56 \pm 6.37$ & $157.18 \pm 6.08$ & $155.74 \pm 5.87$ & $\mathrm{p}<0.05$ \\
\hline Age at menarche in years ${ }^{*}$ & $12.61 \pm 1.50$ & $12.74 \pm 1.56$ & $12.87 \pm 1.7$ & $\mathrm{p}<0.05$ \\
\hline Age at natural menopause in years ${ }^{*}$ & $48.05 \pm 5.26$ & $47.40 \pm 5.59$ & $46.84 \pm 5.7$ & $\mathrm{p}<0.05$ \\
\hline Praecox Menopause $(<40 \text { years })^{* *}$ & $23(6.7 \%)$ & $40(7.3 \%)$ & $36(11.59 \%)$ & $\mathrm{p}<0.05$ \\
\hline Parity ${ }^{*}$ & $2.84 \pm 1.89$ & $2.65 \pm 1.74$ & $2.77 \pm 1.83$ & NS \\
\hline
\end{tabular}

${ }^{*}$ Mean \pm standard error; ${ }^{* *}$ number of cases $(\%)$.

Table 2. Demographic characteristics and BMD at hip.

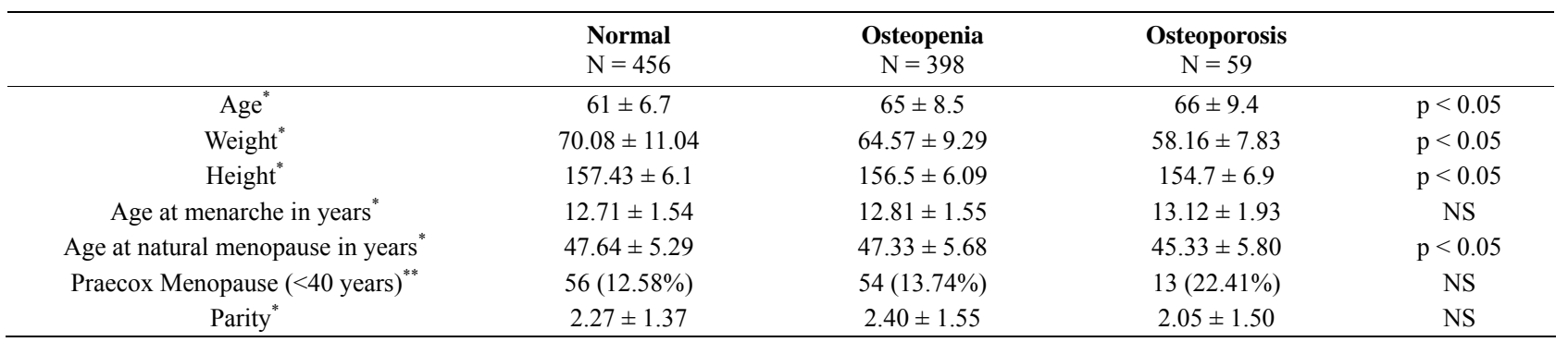

${ }^{*}$ Mean \pm standard error; ${ }^{* *}$ number of cases $(\%)$. 
Table 3. Risk factors (habits and fat distribution) and BMD at lumbar spine.

\begin{tabular}{|c|c|c|c|c|}
\hline & $\begin{array}{l}\text { Normal } \\
\mathrm{N}=479\end{array}$ & $\begin{array}{c}\text { Osteopenia } \\
N=766\end{array}$ & $\begin{array}{c}\text { Osteoporosis } \\
\mathrm{N}=450\end{array}$ & \\
\hline Smokers $^{* *}$ & $102(29.74 \%)$ & $172(31.38 \%)$ & $112(34.78 \%)$ & $\mathrm{p}<0.05$ \\
\hline Moderate alcohol consumers ${ }^{* *}$ & $120(34.9 \%)$ & $161(29.38 \%)$ & $81(25.15 \%)$ & $\mathrm{p}<0.05$ \\
\hline Practice of sport (days at week) ${ }^{*}$ & $4.65 \pm 2.01$ & $4.61 \pm 1.99$ & $4.74 \pm 1.97$ & No \\
\hline $\begin{array}{l}\text { Exercise }{ }^{* *} \\
\text { - Regularity } \\
\text { - Sedentary } \\
\text { - Task at home }\end{array}$ & $\begin{array}{c}188(54.81 \%) \\
57(16.61 \%) \\
94(27.41 \%)\end{array}$ & $\begin{array}{c}310(56.57 \%) \\
80(14.59 \%) \\
36(6.57 \%)\end{array}$ & $\begin{array}{c}182(56.52 \%) \\
37(11.49 \%) \\
102(31.68 \%)\end{array}$ & $\begin{array}{l}\text { No } \\
\text { No } \\
\text { No }\end{array}$ \\
\hline $\begin{array}{l}\text { Fat Distribution }{ }^{* *} \\
\text { - Android } \\
\text { - Ginecoid } \\
\text { - None }\end{array}$ & $\begin{array}{c}75(15.65 \%) \\
192(40.08 \%) \\
202(42.17 \%)\end{array}$ & $\begin{array}{l}135(17.62 \%) \\
291(37.98 \%) \\
331(43.21 \%)\end{array}$ & $\begin{array}{c}69(15.33 \%) \\
169(37.55 \%) \\
197(43.77 \%)\end{array}$ & No \\
\hline
\end{tabular}

${ }^{*}$ Mean \pm standard error; ${ }^{* *}$ number of cases $(\%)$.

Table 4. Risk factors (habits and fat distribution) and BMD at hip.

\begin{tabular}{|c|c|c|c|c|}
\hline & $\begin{array}{l}\text { Normal } \\
N=456\end{array}$ & $\begin{array}{c}\text { Osteopenia } \\
\mathrm{N}=398\end{array}$ & $\begin{array}{c}\text { OP } \\
N=59\end{array}$ & \\
\hline Smokers $^{* *}$ & $124(27.19 \%)$ & $108(27.14 \%)$ & $20(33.90 \%)$ & NS \\
\hline Moderate alcohol consumers $^{* *}$ & $146(32.02 \%)$ & $111(27.89 \%)$ & $16(27.12 \%)$ & NS \\
\hline Practice of sport (days at week) ${ }^{*}$ & $4.78 \pm 2.05$ & $4.67 \pm 2.01$ & $5.58 \pm 1.80$ & NS \\
\hline $\begin{array}{l}\text { Exercise }{ }^{* *} \\
\text { - Regularity } \\
\text { - Sedentary } \\
\text { - Task at home }\end{array}$ & $\begin{array}{c}241(52.85 \%) \\
63(13.82 \%) \\
152(33.33 \%)\end{array}$ & $\begin{array}{c}246(61.81 \%) \\
43(10.80 \%) \\
110(27.64 \%)\end{array}$ & $\begin{array}{c}40(67.79 \%) \\
5(8.47 \%) \\
14(23.73 \%)\end{array}$ & $\begin{array}{l}\text { NS } \\
\text { NS } \\
\text { NS }\end{array}$ \\
\hline $\begin{array}{l}\text { Fat Distribution }{ }^{* *} \\
\text { - Android } \\
\text { - Ginecoid } \\
\text { - None }\end{array}$ & $\begin{array}{c}43(9.64 \%) \\
222(49.77 \%) \\
181(40.58 \%)\end{array}$ & $\begin{array}{c}40(10.28 \%) \\
185(47.55 \%) \\
163(41.90 \%)\end{array}$ & $\begin{array}{c}4(6.89 \%) \\
16(28.07 \%) \\
37(64.91 \%)\end{array}$ & NS \\
\hline
\end{tabular}

${ }^{*}$ Mean \pm standard error; ${ }^{* *}$ number of cases $(\%)$.

There was a direct correlation between the consumption of vegetables, fruit, dairy, cereals, and fish with BMD in the spine. However, only the consumption of vegetables and cereals was correlated with BMD in the femoral neck, and the remaining variables were not significantly associated with BMD. Again, due to the smaller sample size available for the analysis of hipbone density, the differences between osteoporosis, osteopenia, and normal BMD exhibited trends but did not achieve statistical significance; in the larger set of lumbar spine data, these differences became significant. Strikingly, lower BMD was correlated with the consumption of red meat, and increased BMD was associated with the consumption of fruit, vegetables, cereals, dairy, or fish (Tables 5 and 6).

\section{DISCUSSION}

Postmenopausal osteoporosis is a complex and multifactorial process that accompanies aging. It is an important public health issue because it is associated with the increased incidence of characteristic fractures near the end of life, which is especially relevant in aging populations, particularly in industrialized societies. Our data seem to confirm that osteoporosis is an estrogen-dependent disease and that women who have had shorter fertile periods are more likely to develop the disease [4]. We observed a relationship between BMD and age at menarche, age at menopause, and overall reproductive life span. The average age of menarche was later in the group of osteoporotic patients, although this difference was not statistically significantly correlated with femoral neck BMD. The age of menopause was lower in the group with osteoporosis than in the other two groups. We also confirmed that the incidence of early menopause was higher among women with lower BMD. Wrist fractures occur between 45 and 65 years of age, vertebral fractures occur after age 70 years and hip fractures usually occur after 80 years [5].

A balanced diet is important for bone development and maintenance, as well as for general health. Some populations, such as women over age 65 , edentulous women, women with reduced appetites from any cause, or women who diet frequently or have eating disorders, may not consume adequate vitamins and minerals to maintain optimal bone mass. Older women who lose weight, purposely or not, run the risk of accelerated bone 
Table 5. Type of food intaken and BMD at lumbar spine.

\begin{tabular}{ccccc}
\hline & Normal & Osteopenia & \multicolumn{2}{c}{ OP } \\
& $\mathrm{N}=479$ & $\mathrm{~N}=766$ & $\mathrm{~N}=450$ & $\mathrm{p}<0.05$ \\
\hline Fruit/day $^{*}$ & $2.46 \pm 1.32$ & $2.26 \pm 1.28$ & $1.95 \pm 1.11$ & $\mathrm{p}<0.05$ \\
Vegetables/day $^{*}$ & $1.60 \pm 1.12$ & $1.51 \pm 1.02$ & $1.38 \pm 0.7$ & $\mathrm{p}<0.05$ \\
Cereals/day $^{*}$ & $1.23 \pm 1.07$ & $1.12 \pm 1.11$ & $0.86 \pm 0.87$ & $\mathrm{NS}$ \\
Food in preserve/day $^{*}$ & $0.43 \pm 0.62$ & $0.43 \pm 0.62$ & $0.43 \pm 0.59$ & $\mathrm{p}<0.05$ \\
Dairy products/day $^{*}$ & $2.64 \pm 1.42$ & $2.41 \pm 1.29$ & $2.15 \pm 1.08$ & $\mathrm{p}<0.05$ \\
Red meat/week $^{*}$ & $1.39 \pm 1.21$ & $1.71 \pm 1.42$ & $1.94 \pm 1.48$ & $\mathrm{p}<0.05$ \\
Fish/week & $2.82 \pm 1.41$ & $2.55 \pm 1.38$ & $2.26 \pm 1.18$ & \\
\hline
\end{tabular}

*Mean \pm standard error.

Table 6. Type of food intaken and BMD at hip.

\begin{tabular}{ccccc}
\hline & Normal & Osteopenia & OP & \\
& $\mathrm{N}=343$ & $\mathrm{~N}=548$ & $\mathrm{~N}=322$ & \\
\hline Fruit/day $^{*}$ & $2.02 \pm 1.20$ & $2.12 \pm 1.17$ & $2.14 \pm 1.16$ & $\mathrm{NS}$ \\
Vegetables/day $^{*}$ & $1.31 \pm 0.90$ & $1.37 \pm 0.84$ & $1.29 \pm 0.85$ & $\mathrm{p}<0.05$ \\
Cereals/day $^{*}$ & $0.91 \pm 0.98$ & $1.04 \pm 1.07$ & $0.68 \pm 0.99$ & $\mathrm{p}<0.05$ \\
Food in preserve/day $^{*}$ & $0.09 \pm 0.64$ & $0.05 \pm 0.67$ & $0.08 \pm 0.62$ & $\mathrm{NS}$ \\
Dairy products/day $^{*}$ & $2.27 \pm 1.28$ & $2.42 \pm 1.27$ & $2.07 \pm 1.05$ & $\mathrm{NS}$ \\
Red meat/week $^{*}$ & $1.46 \pm 1.46$ & $1.34 \pm 1.43$ & $1.53 \pm 1.60$ & $\mathrm{NS}$ \\
Fish/week & $2.55 \pm 1.37$ & $2.59 \pm 1.41$ & $2.56 \pm 1.49$ & $\mathrm{NS}$ \\
\hline
\end{tabular}

${ }^{*}$ Mean \pm standard error.

loss and a higher risk of hip fracture [6].

Lifestyle approaches alone may not be sufficient to prevent bone loss or reduce fracture risk, but they form the necessary foundation for pharmacologic approaches to the prevention or management of osteoporosis. In some cases, recommended lifestyle approaches may be sufficient. All postmenopausal women, regardless of their bone density or clinical risk factors for osteoporosis, should be encouraged to eat a balanced diet, obtain adequate calcium and vitamin D [7].

The "Mediterranean diet" is part of a lifestyle based on the idealization of the eating patterns of Mediterranean countries, especially the eastern Mediterranean region. The main features of this diet are an emphasis on vegetables (fruits, vegetables, legumes, nuts, bread, and other cereals), the use of olive oil as the main fat, the consumption of poultry and fish rather than red meat and the regular consumption of wine in moderate amounts. The main benefits of this diet are the reduced consumption of animal fats, the increased consumption of fish, especially oily fish, which are rich in omega- 3 fatty acids, and the high consumption of olive oil, which contains relatively low levels of saturated fat ( $7 \%$ to $8 \%$ of total calories). This diet usually promotes a total fat intake between $25 \%$ and just over $35 \%$ of total calories. The inclusion of wine in this diet is also beneficial because red wine contains anthocyanins. Finally, this diet is rich in antioxidant compounds due to the high daily intake of fresh fruit and vegetables [8].

The Mediterranean diet has been associated with lower cardiovascular risk, lower total cholesterol [9], lower incidence of stroke, lower endothelial dysfunction [10], and a decrease in the incidence of metabolic diseases and an improvement in the severity of these diseases, such as diabetes mellitus [11] or metabolic syndrome [12]. Moreover, according to data from the NHANES III study [13], BMD is negatively associated with the intake of saturated fat. Thus, a diet rich in omega- 3 and omega- 6 fatty acids has beneficial effects on bone mass and, moreover, is associated with decreased mortality due to cardiovascular disease.

Other authors have also noted the possibility that diet can affect bone strength. The pathophysiological basis of this relationship is unknown, although two possibilities have been hypothesized. First, certain foods are rich in vitamin D [14] and contain a high concentration of unsaturated fatty acids (omega-3, -6 or -9 ) [15], along with some antioxidants [16]; these substances could have a beneficial effect on bone mass in addition to their favorable cardiovascular effects. It is also known that BMD decreases with the increased intake of saturated fat contained in meat products.

Here, we found a dose-dependent relationship between the consumption of these foods and BMD. Following the EVOS study [17], which highlighted the importance of diet, particularly dairy products, in preventing osteopo- 
rosis, other studies investigated the effects of other substances that are rich in vitamins and minerals with antioxidant and alkaline effects and showed that these foods are associated with the achievement of higher peak bone mass during adolescence and less rapid loss of bone density after menopause [18-20].

Even though this study is limited by its observational nature, it is one of the few studies in which bone health has been linked to the Mediterranean diet. The study found a direct relationship between BMD and dietary factors such as the elevated consumption of fruits, vegetables and grains, the moderate intake of dairy products, fish and alcohol, and the low intake of red meat, in the context of the "Mediterranean" style of eating.

Although osteoporosis is a systemic disease, the pathophysiological mechanisms involved in its development may differ depending on the type of bone (i.e., trabecular vs cortical bone). Thus, the effects of specific environmental factors may also differ between trabecular and cortical bone. In this regard, we note that while certain dietary factors protect against osteoporosis in general, some factors only protect against spinal osteoporosis, e.g., the increased consumption of fruits, vegetables, fish, and dairy products; moderate consumption of alcohol; and low intake of red meat and tobacco. In contrast, cereal and vegetable intake was associated with higher $\mathrm{BMD}$ in both the spine and the femoral neck.

In conclusion, the epidemiological characteristics of our population of postmenopausal women exhibit a pattern similar to that described in other studies, showing a proportional relationship between the magnitude of the risk factor and the severity of osteopenia/osteoporosis. Moreover, we observed protective effects for several dietary factors, such as the consumption of fruits, vegetables, and cereals; the moderate consumption of fish, alcohol, and dairy products; and the low intake of red meat, on spinal BMD. Only the intake of grains and vegetables exerted protective effects on hip BMD.

\section{REFERENCES}

[1] Delaney, M.F. (2006) Strategies for the prevention and treatment of osteoporosis during early ostmenopause. American Journal of Obstetrics \& Gynecology, 194, S12S23. doi:10.1016/j.ajog.2005.08.049

[2] Cummings, S.R., Nevitt, M.C., Browner, W.S., et al., Study of Osteoporotic Fractures Research Group (1995) Risk factors for hip fracture in white women. The New England Journal of Medicine, 332, 767-773. doi:10.1056/NEJM199503233321202

[3] Lambrinoudaki, I., Ceasu, I., Depypere, H., Erel, T., Rees, M., Schenck-Gustafsson, K., Simoncini, T., Tremollieres, F., van der Schouw, Y.T. and Pérez-López, F.R. (2013) EMAS position statement: Diet and health in midlife and beyond. Maturitas, 74, 99-104. doi:10.1016/j.maturitas.2012.10.019

[4] Lane, N.E. (2006) Epidemiology, etiology, and diagnosis of osteoporosis. American Journal of Obstetrics \& Gynecology, 194, S3-S11. doi:10.1016/j.ajog.2005.08.047

[5] Harvey, N., Dennison, E. and Cooper, C. (2010) Osteoporosis: Impact on health and economics nature reviews. Rheumatology, 6, 99-105.

[6] Ensrud, K.E., Ewing, S.K., Stone, K.L., Cauley, J.A., Bowman, P.J., Cummings, S.R., Study of Osteoporotic Fractures Research Group (2003) Intentional an unintentional weight loss increase bone loss and hip fracture risk in older women. Journal of the American Geriatrics Society, 51, 1740-1747. doi:10.1046/j.1532-5415.2003.51558.x

[7] The North American Menopause Society (2010) Management of osteoporosis in postmenopausal women: 2010 position statement of The North American Menopause Society. Menopause, 17, 25-54. doi:10.1097/gme.0b013e3181c617e6

[8] Keys, A.B. and Keys, M. (1975) How to eat well and stay well. The Mediterranean way. Doubleday, New York.

[9] Giugliano, D. and Esposito, K. (2008) Mediterranean diet and metabolic diseases. Current Opinion in Lipidology, 19, 63-68.

[10] Esposito, K., Marfella, R., Ciotola, M., et al. (2004) Effect of a Mediterranean-style diet on endothelial dysfunction and markers of vascular inflammation in the metabolic syndrome: A randomized trial. JAMA, 292, 14401446. doi:10.1001/jama.292.12.1440

[11] Schröder, H. (2007) Protective mechanisms of the Mediterranean diet in obesity and type 2 diabetes. The Journal of Nutritional Biochemistry, 18, 149-160. doi:10.1016/j.jnutbio.2006.05.006

[12] Esposito, K., Ciotola, M. and Giugliano, D. (2007) Mediterranean diet and the metabolic syndrome. Molecular Nutrition \& Food Research, 51, 1268-1274.

[13] Corwin, R.L., Hartman, T.J., Maczuga, S.A. and Graubard, B.I. (2006) Dietary saturated fat intake is inversely associated with bone density in humans: Analysis of NHANES III. Journal of Nutrition, 136, 159-165.

[14] Kitchin, B. and Morgan, S.L. (2007) Not just calcium and vitamin D: Other nutritional considerations in osteoporosis. Current Rheumatology Reports, 9, 85-92. doi:10.1007/s11926-007-0027-9

[15] Ward, W.E. and Fonseca, D. (2007) Soy isoflavones and fatty acids: Effects on bone tissue postovariectomy in mice. Molecular Nutrition \& Food Research, 51, 824 831. doi: $10.1002 / \mathrm{mnfr} .200600187$

[16] Altindag, O., Erel, O., Soran, N., Celik, H. and Selek, S. (2008) Total oxidative/anti-oxidative status and relation to bone mineral density in osteoporosis. Rheumatology International, 28, 317-321. doi:10.1007/s00296-007-0452-0

[17] Lunt, M., Masaryk, P., Scheidt-Nave, C., et al. (2001) The effects of lifestyle, dietary dairy intake and diabetes on bone density and vertebral deformity prevalence: The EVOS study. Osteoporosis International, 12, 688-698. doi:10.1007/s001980170069 
[18] Cashman, K.D. (2007) Diet, nutrition, and bone health. Journal of Nutrition, 137, 2507S-2512S.

[19] Puel, C., Coxam, V. and Davicco, M.J. (2007) Mediterranean diet and osteoporosis prevention. Médecine Sciences (Paris), 23, 756-760.

\section{doi:10.1051/medsci/20072389756}

[20] Coxam, V. (2005) New advances in osteoporosis nutritional prevention. Médecine Sciences (Paris), 21, 297301. doi:10.1051/medsci/2005213297 